\title{
Penerapan Metode SDLC Waterfall Dalam Pembuatan Sistem Informasi Akademik Berbasis Web Studi Kasus Pondok Pesantren Al-Habi Sholeh Kabupaten Kubu Raya, Kalimantan Barat
}

\author{
Yoki Firmansyah ${ }^{[1]}, \mathbf{U d i}^{[2]}$ \\ yoki.yry@bsi.ac.id ${ }^{[1]}$ udi1608@bsi.ac.id ${ }^{[2]}$ \\ Program Studi Manajemen Informatika, AMIK BSI Pontianak ${ }^{[1][2]}$
}

\begin{abstract}
Academic Information System is one of the information that is needed by educational institutions as one As reference for the development and achievement of teaching and learning activities. Academic information systems can also spur teachers to be more transparent in delivering learning outcomes to students and also spur students in improving learning outcomes, so that has more meaning as a communication between teachers and students. This system will also spur all to know the development of boarding school because the existing information system at Al-habib Pondok Pesantren Sholeh Bin Alwi Alhaddad, Currently, Alhabib use the manual system to data processor ex stundents, assessment and processing of academic information. With the existence of this academic information system it will facilitate the admin to provide academic information, facilitate the teacher in providing assessments of students didiknya more easily and transparently, facilitate students and parents learn mngetahui student development. The website also has feature facilitate all obtain information relating to boarding school and will further spur all in using the internet by accessing the academic website of Pesantren Al-habib sholeh Bin Alwi Al-haddad.
\end{abstract}

Keywords: Pembuatan Sistem Akademik, Pesantren Al-habib Sholeh, Berbasis Web

\section{PENDAHULUAN}

Pada saat ini Teknologi Informasi mengalami perkembangan yang sangat cepat. Tidak sedikit orang menggunakan aplikasi sebagai alat bantu dalam pengambilan keputusan dan aplikasi tersebut digunakan sebagai bahan untuk memperoleh hasil pencarian dari suatu pokok permsalahan. diharapkan hasilnya akan memeberikan solusi serta mengambil keputusan dengan tepat. Pada lembaga pendidikan yang penerapan sistem informasi akademik dapat meningkatkan performa kegiatan akademik, dikarenakan penerapan sistem informasi dapat memperoleh informasi yang cepat dan tepat pada saat dibutuhkan. Informasi akademik di rancang untuk keperluan pengolahan data akademik dengan penerapan teknaologi komputer. Sehingga seluruh proses kegiatan akademik dapat dikelola menjadi informasi yang bermanfaat.

Selama ini dalam segala pengarsipan terutama pada Madrasah Aliyah Pondok Pesantren Al Habib Sholeh Bin Alwi Al haddad masih menggunakan pencatatan buku maupun kertas yang di simpan pada buku induk seperti untuk menyimpan Data Guru, Santri Dan Nilai, Yang Mengakibatkan Data yang berupa kertas dapat berakibat terjadinya pencatatan yang berulang, kerusakan seperti berkas hilang atau pun rusak. begitu juga dalam hal informasi akademik masih terbatas seperti informasi akademik yang di terapkan masih mengunakan kertas.

Informasi akademik adalah sebuah sistem yang di rancang untuk keperluan pengolaan data akademik dengan penerapan teknaologi komputer. Sehingga seluruh proses kegiatan akademik dapat dikelola menjadi informasi yang bermanfaat dalam pengelolaan manajemen lembaga dan untuk pengambilan keputusan Dan untuk menghindari atau meminimalisasi terjadinya kesalahan yang di dalamnya mencakup aspek-aspek pelayanan sehingga dapat memberiakan informasi-informasi yang dibutuhkan.

Berdasarkan latar belakang yang terjadi di Madrasah Aliyah Pondok Pesantren Al Habib Sholeh Bin Alwi Al haddad yang telah dijelaskan sebelumnya penulis berusaha menerapkan Informasi akademik, dimana sebuah sistem yang di rancang untuk keperluan pengolaan data akademik Madrasah Aliyah Pondok Pesantren Al Habib Sholeh Bin Alwi Al haddad dengan penerapan teknaologi komputer. Sehingga seluruh proses kegiatan akademik dapat dikelola menjadi informasi yang bermanfaat dalam pengelolaan manajemen.

Dengan demikian dilihat dari masalah seperti yang di jelaskan diatas penulis mengambil judul "Pembuatan Sistem Informasi Akademik Berbasis Web Pada Pondok Pesantren Al-habib Sholeh Bin Alwi Al-haddad Kec. Sungai Ambawang Kabupaten Kubu Raya."

\subsection{Rumusan Masalah}

- Bagaimana membuat sistem informasi akademik berbasis web pada Pondok Pesantren Al habib Sholeh Bin Alwi Alhaddad dengan mengikuti metodologi SDLC Waterwall

- Bagaimana melaksanakan proses pengolahan data siswa, guru, nilai dan informasi akademik

- Bagaimana memberikan informasi terhadap orang tua dan untuk umum tentang kegiatan yang di lakukan lembaga. 


\subsection{Maksud dan Tujuan} berikut;

Adapun maksud dan tujuan adalah sebagai

- Mempelajari dan menerapkan sistem terkomputerisasi dalam pengolahan data guru, siswa, nilai, dan informasi pada madrasah aliyah pondok pesantren Al Habib Sholeh Bin Alwi Al Haddad yang selama ini masih menggunakan pencatatan yang di simpan ke buku induk dan seringnya pencatan data yang berulang

- Kesulitan dalam hal penyampaian informasi perkembangan siswa kepada orang tua siswa.

- Memberikan wadah komunikasi santri dan orang tua santri tentang informasi dan kegiatan santri.

- Dapat memberikan solusi yang lebih baik dari setiap permasalahan yang dialami Madrasah Aliyah Pondok Pesantren Al Habib Sholeh Bin Alwi Al Haddad.

\subsection{Ruang Lingkup}

Bersadarkan Rumusan Masalah yang telah penulois identifikasi maka didapatlah ruang lingkup pada penelitian ini yaitu hanya membahas pemograman Web Sistem Informasi Akademik yang menggunakan metodologi waterfall Meliputi Pendataan Guru, Pendataan Santri, Pendataan Nilai Dan Informasi Akademik pada Madrasah Aliyah Pondok Pesantren Al Habib Sholeh Bin Alwi Al haddad. Yang dimana Sistem ini hanya dapat gunakan oleh Admin, Guru, wali kelas MA dan Santri MA. Tetapi Sistem informasi akademik ini tidak di kususkan untuk MI dan MTs.

\section{TINJAUAN PUSTAKA}

\subsection{Internet}

Menurut Irawan (2011:2) mengemukakan bahwa "Internet merupakan kependekan dari kta Internetwork yang berarti rangkaian Komputer yang terhubung menjadi beberapa rangkaian jaringan. Sedangkan Menurut Arief (2011:7) mengemukakan bahwa "Web adalah salah satu aplikasi yang berisikan dokumen-dokumen multimedia (teks, gambar, suara, animasi,video) di dalamnya yang menggunakan protokol HTTP (hypertext transfer protocol) dan untuk mengaksesnya menggunakan perangkat lunak yang disebut browser". Sedangkan Menurut Dipraja (2013:10) mengemukakan bahwa "web page (halaman web) adalah sebuah halaman khusus dari situs web tertentu, sedangkan homepage adalah sampul halaman yang berisi daftar isi atau menu dari sebuah situs web."

Menurut Simarmata (2010:148) Mendefinisikan bahwa "PHP (Hypertext Preprocessor) adalah PHP mengijinkan pengembang untuk menempelkan kode didalam HTML dengan menggunakan bahasa yang sama seperti perl dan UNIX shells."

Menurut Kadir Dan Triwahyuni (2013:321) "HTML adalah bahasa markah yang digunakan untuk menyusun halaman Web".

Menurut Kadir (2013:15) mengemukakan bahwa "MySQL adalah nama database server, database server adalah server yang berfungsi untuk me- nangani database, MySQL adalah database Server yang sangat populer dan banyak digunakan untuk menangani data yang disajikan di halaman web."

Menurut Sibero (2013:112) "cascading style sheet" dikembangkan untuk menata gaya pengaturan halaman web. terdiri dari Selector properti dan nilai seperti halnya HTML atau PHP dan bahasa pemograman lainnya."

\subsection{Sistem Informasi Akademik}

Menurut Prasojo dan Riyanto (2011:152) Sistem adalah elemen-elemen yang terintegrasi dan saling berhubungan untuk mencapai suatu tujuan yang diinginkan

Menurut Pratama (2014:9) "informasi adalah merupakan hasil pengolahan data dari satu atau berbagai sumber yang kemudian diolah, sehingga memberikan nilai, arti dan manfaat." Sedangkan menurut Kadir dan Triwahyuni(2013:384) "informasi merupakan salah satu sumber daya penting dalam suatu organisai dalam pengambilan keputusan"

Menurut Agus Saputra (2012:11) "Sistem Akademik merupakan sistem yang diciptakan dan digunakan untuk memenuhi kebutuhan manajemen kampus." sistem informasi akademik adalah perangkat lunak yang digunakan untuk menyajikan informasi dan penata administrasi yang berhubungan dengan penggunaan perangkat lunak seperti kegiatan administrasi akademik dapat dikelola dengan baik dan informasi yang di perlukan dapat diperoleh dengan mudah dan cepat (Satoto, 2008)

\subsection{Model Pengembangan Waterfall}

Model Waterfall merupakan salah satu model pengembangan perangkat lunak yang ada di dalam model SDLC (Sequencial Development Life Cycle). Menurut Sukamto dan Shalahuddin (2013:26) mengemukakan bahwa "SDLC atau Software Development Life Cycle atau sering disebut juga System Development Life Cycle adalah proses mengembangkan atau mengubah suatu sistem perangkat lunak dengan menggunakan model-model dan metodologi yang digunakan orang untuk mengembangkan sistem-sistem perangkat lunak sebelumnya, berdasarkan best practice atau cara-cara yang sudah teruji baik."

Sedangkan Sukamto dan Shalahuddin (2013:28) di jelaskan bahwa model waterfall sering juga disebut model sekuensi linear atau alur hidup klasik. Pengembangan sistem dikerjakan secara terurut mulai dari analisis, desain, pengkodean, pengujian dan tahap pendukung.

\section{METODOLOGI}

Terdapat beberapa metode yang digunakan dalam melakukan penelitian ini, diantaranya yaitu :

a. Metode Penulisan

Pada penelitian ini penulis menggunakan metode penulisa yang bersifat deskriptif dimana dalam penulisan desktiptif hasil dari penelitian di tuliskan secara jelas dan mendeskripsikan inti dari penulisan b. Metode Pengembangan Perangkat Lunak 
Pada penelitian ini selain menggunakan metode penulisan, penulis juga menggunakan metode pengembangan perangkat lunak untuk mengembangkan Sistem Informasi Akademik berbasis Web Ini, adapun metode yang digunakan adalah SDLC Waterfall yang disadur dari buku Sukamto dan Shalahuddin tahun 2013. Adapun penjelasan dari metode ini adalah sebagai berikut :

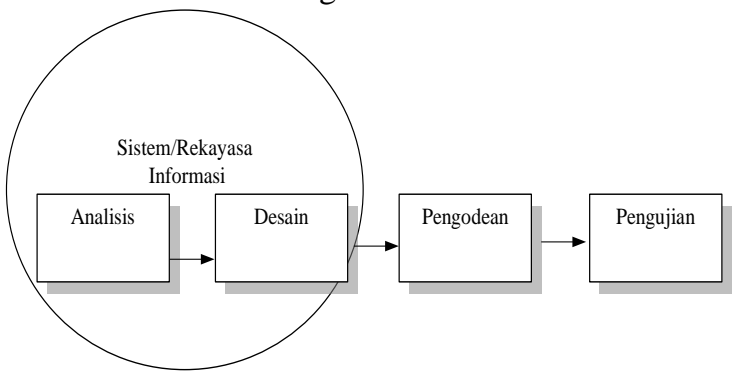

Sumber :Sukamto dan Shalahuddin (2013:29)

Gambar 1. Kerangka Penelitian

\section{- Analisis}

- Dalam tahap ini penulis mulai menganalisa apa saja kebutuhan dari system, mulai dari kebutuhan fungsional system maupun kebutuhan non fungsional dari sistem

- Desain

Tahap desain merupakan tahapan lanjut dari tahap analisis dimana dalam tahap ini disajikan desain desain dari aplikasi seperti desain antar muka, dan desain data base yang akan diterapkan kedalam system Informasi Akademik yang akan dibuat

\section{- Pengkodean}

Pada tahap ini penulis menerapkan desai data base serta desain antar muka kedalam bahasa pemrograman, dimana bahasa pemrograman yang dipakai adalah menggunakan bahasa PHP untuk website

- Pengujian

Tahap uji merupakan tahap akhir dalam metode waterfall dimana dalam tahap pengujian ini digunakan teknik pengujian blackbox testing

\section{PEMBAHASAN}

\subsection{Tahap Analisis Kebutuhan Perangkat Lu-} nak

Dalam penelitian ini penulis akan membahas tentang Sistem Informasi Akademik Berbasis Web pada Pondok Pesantren Alhabib Sholeh Bin Alwi Alhaddad menggunakan metode SDLC Waterfall dimana tahap pertamanya adalah tahap analisa, adapun hasil analisa kebutuhan yang dilakukan yaitu sebagai berikut :

\section{- Kebutuhan Fungsional}

Tahap keutuhan fungsional ini di perlukan untuk mengindifikasi apa saja yang dibutuhkan dan di inginkan oleh pengguna dari Aplikasi Sistem Informasi Akademik pada Pondok Pesantren Alhabib Sholeh in Alwi Al-haddad adapun kebutuhan Fungsional adalah sebagai berikut:

1. Admin
- Admin membutuhkan Username dan Password untuk bisa Login.

- Menambahkan Admin, Untuk menambahkan data admin user membutuhkan Nama Admin, Username, Password dan Foto untuk di simpan ke database.

- Menambahkan Data guru, Untuk menambahkan data Guru user membutuhkan kode guru, Nip, nama guru, jenis kelamin, Alamat, telepon, status, foto, password dan mata pelajaran yang di ambil agar bisa di simpan ke database.

- Menambahkan Data wali kelas, Untuk menambahkan data wali kelas user membutuhkan nama guru, kelas, username dan password agar bisa di simpan ke database.

- Menambahkan Data siswa, Untuk menambahkan data siswa user membutuhkan kode siswa, nama siswa, nis, nik, jenis kelamin, tempat lahir, tanggal lahir, alamat siswa, no telpon, foto, nama ayah, nama ibu, alamat ortu, pekerjaan ayah, pekerjaan ibu, no telpon, nama wali dan alamat wali agar bisa di simpan ke database.

- Menambahkan Data Mata Pelajaran, Untuk menambahkan data mata pelajaran admin membutuhkan kode pelajaran, nama pelajaran, kelas dan keterangan agar bisa di simpan ke database.

- Membberikan Informasi Akademik, Saat admin menambahkan informasi maka akan tampil nama admin sebagai penanggung jawab agar dapat di simpan ke database dan akan di tampilkan kehalaman utama sistem akademik

2. Guru

Untuk mengisi nilai siswa Guru harus login terlebih dahulu, dengan menggunakan Username Dan Password yang teleh di perolehnya dari Admin setelah itu guru akan masuk sistem kehalaman Guru, yang di dalam halaman guru terdapat menu masukan nilai untuk mengisi nilai sesuai kebutuhan Guru.

3. Siswa

Untuk mengetahui nilai dan informasi siswa harus login terlebih dahulu menggunakan NIS sebagai Username dan Tanggal lahir sebagai password agar dapat masuk ke sistem siswa, setelah login siswa dapat melihat informasi yang dikirimkan oleh masing-masing wali kelas siswa dan siswa dapat melihat nilai masing mata pelajaran atau seluruh mata pelajaran, siswa juga dapat mencetak nilai siswa keseluruhan sesuai yang telah disediakan sistem.

4. Wali Kelas

Untuk memasuki sistem wali kelas membutukan username dan pasword untuk dapat masuk ke halaman wali kelas, setelah login wali kelas hanya dapat memberikan informasi yang dapat tampil di setiap masing-masing halaman beranda siswa setelah siswa melakukan login sesuai status wali kelas.

\section{- Kebutuhan Non Fungsional}

Dalam Tahapan kebutuhan Non fungsional ini penulis mengindifikasi apa saja yang dibutuhkan oleh pengguna untuk menjalankan Aplikasi Sistem 
Informasi Akademik pada Pondok Pesantren AlHabib Sholeh in Alwi Al-haddad.

1. Spesifikasi Perangkat Keras

- Server

CPU Intel Core i3-5005U (2.0 GHz, 3 MB L3

Cache), RAM 4 GB, Harddisk 500 Gb, Mouse, Keyboard, Monitor Dengan Resolusi Layar Minimum 1366 X 768, Kecepatan Internet 1 Mbps

- Client

CPU, Intel Core i3-5005U (2.0 GHz, 3 MB L3 Cache), RAM 4 GB, Harddisk 500 GB, Mouse , Keyboard, Monitor Dengan Resolusi Layar Minimum 1366 X 768, Kecepatan Internet 1 Mbps,

2. Spesifikasi Perangkat Lunak

- Server

Paket Hosting, Domain Ponpes-Alhaddad.Ac.Id, Microsoft Windows 7, Google Chrome, Mozila Firefox, Opera

- Client

Microsoft Windows 7, Google Chrome, Mozila Firefox, Opera

\subsection{Tahap Desain}

\section{a. ERD ((Entity Relationship Diagram)}

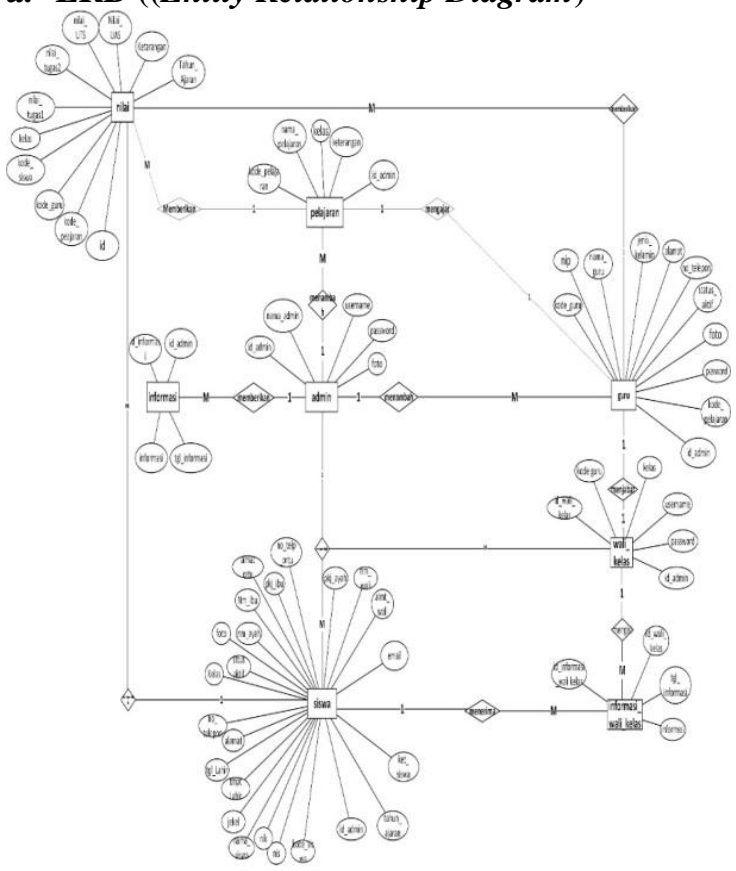

Gambar 2. ERD (Entity Relationship Diagram)

b. LRS

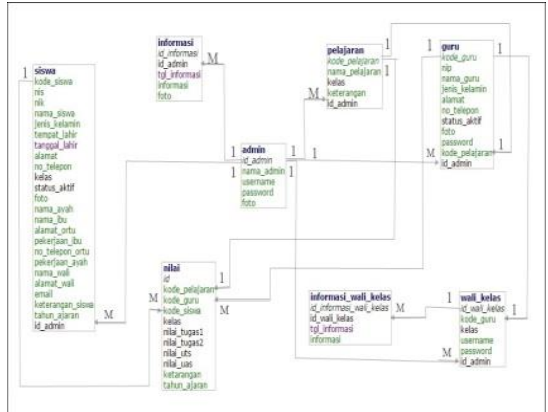

Gambar 3. LRS (Logical Relational Strukture)

c. Desain Database

- Spesifikasi File Admin
Tabel 1. Spesifikasi File Admin

\begin{tabular}{|l|l|l|l|l|l|}
\hline No & Elemen Data & Nama Field & Type & Size & Keterangan \\
\hline 1 & Id_Admin & Id_Admin & Int & 10 & Primary Key \\
\hline 2 & Nama_Admin & Nama_Admin & Varchar & 25 & \\
\hline 3 & Username & Username & Varchar & 25 & \\
\hline 4 & Password & Password & Varchar & 50 & \\
\hline 5 & Foto & Foto & Varchar & 100 & \\
\hline
\end{tabular}

- $\quad$ Spesifikasi File Guru

Tabel 2. Spesifikasi File Guru

\begin{tabular}{|l|l|l|l|l|l|}
\hline No & Elemen data & Nama field & Type & Size & Keterangan \\
\hline 1 & Kode_guru & Kode_guru & Varchar & 10 & $\begin{array}{l}\text { Primary } \\
\text { key }\end{array}$ \\
\hline 2 & Nip & Nip & Varchar & 20 & \\
\hline 3 & Nama_guru & Nama_guru & Varchar & 25 & \\
\hline 4 & Jenis_kelamin & Jenis_kelamin & Char & 1 & \\
\hline 5 & Alamat & Alamat & Varchar & 50 & \\
\hline 6 & No_telepon & No_telepon & Varchar & 20 & \\
\hline 7 & Status_aktif & Status_aktif & Int & 1 & \\
\hline 8 & Foto & Foto & Varchar & 100 & \\
\hline 9 & Password & Password & Varchar & 50 & \\
\hline 10 & Kode_pelajaran & Kode_pelajaran & Varchar & 10 & $\begin{array}{l}\text { Foreign } \\
\text { key }\end{array}$ \\
\hline 11 & Id_admin & Id_admin & Int & 10 & \\
\hline
\end{tabular}

Spesifikasi File Siswa

Tabel 3. Spesifikasi File Siswa

\begin{tabular}{|c|c|c|c|c|}
\hline Elemen data & $\begin{array}{l}\text { Nama } \\
\text { field }\end{array}$ & Type & Size & $\begin{array}{l}\text { Ket- } \\
\text { erangan }\end{array}$ \\
\hline Kode_siswa & $\begin{array}{l}\text { Kode_sisw } \\
\text { a }\end{array}$ & Varchar & 10 & $\begin{array}{l}\text { Primary } \\
\text { key }\end{array}$ \\
\hline Nis & Nis & Varchar & 20 & \\
\hline Nik & Nik & Varchar & 20 & \\
\hline Nama_siswa & $\begin{array}{l}\mathrm{Na}- \\
\text { ma_siswa }\end{array}$ & Varchar & 25 & \\
\hline $\begin{array}{l}\text { Jenis_kelami } \\
\mathrm{n}\end{array}$ & $\begin{array}{l}\text { Jenis_kela } \\
\text { min }\end{array}$ & Char & 1 & \\
\hline Tempat_lahir & $\begin{array}{l}\text { Tem- } \\
\text { pat_lahir }\end{array}$ & Varchar & 25 & \\
\hline Tanggal_lahir & $\begin{array}{l}\text { Tang- } \\
\text { gal_lahir }\end{array}$ & Date & & \\
\hline Alamat & Alamat & Text & & \\
\hline No_telepon & $\begin{array}{l}\text { No_telepo } \\
n\end{array}$ & Varchar & 20 & \\
\hline Kelas & Kelas & Int & 1 & \\
\hline Status_aktif & $\begin{array}{l}\text { Sta- } \\
\text { tus_aktif }\end{array}$ & Int & 1 & \\
\hline Foto & Foto & Varchar & 100 & \\
\hline Nama_ayah & $\begin{array}{l}\mathrm{Na-} \\
\text { ma_ayah }\end{array}$ & Varchar & 25 & \\
\hline Nama_ibu & Nama_ibu & Varchar & 25 & \\
\hline Alamat_ortu & $\begin{array}{l}\text { Ala- } \\
\text { mat_ortu }\end{array}$ & Varchar & 100 & \\
\hline $\begin{array}{l}\text { Peker- } \\
\text { jaan_ibu }\end{array}$ & $\begin{array}{l}\text { Peker- } \\
\text { jaan_ibu }\end{array}$ & Varchar & 25 & \\
\hline $\begin{array}{l}\text { No_telepon_ } \\
\text { ortu }\end{array}$ & $\begin{array}{l}\text { No_telepo } \\
\text { n_ortu }\end{array}$ & Varchar & 20 & \\
\hline $\begin{array}{l}\text { Peker- } \\
\text { jaan_ayah }\end{array}$ & $\begin{array}{l}\text { Peker- } \\
\text { jaan_ayah }\end{array}$ & Varchar & 25 & \\
\hline Nama_wali & $\begin{array}{l}\text { Na- } \\
\text { ma_wali }\end{array}$ & Varchar & 25 & \\
\hline
\end{tabular}




\begin{tabular}{|l|l|l|l|l|}
\hline Alamat_wali & $\begin{array}{l}\text { Ala- } \\
\text { mat_wali }\end{array}$ & Varchar & 100 & \\
\hline Email & Email & Varchar & 50 & \\
\hline $\begin{array}{l}\text { Ket- } \\
\text { erangan_sisw } \\
\text { a }\end{array}$ & $\begin{array}{l}\text { Ket- } \\
\text { erangan_s } \\
\text { iswa }\end{array}$ & Text & & \\
\hline Tahun_ajaran & $\begin{array}{l}\text { Ta- } \\
\text { hun_ajara } \\
n\end{array}$ & Varchar & 10 & \\
\hline Id_admin & Id_admin & Int & 10 & \\
\hline
\end{tabular}

- $\quad$ Spesifikasi File Nilai

Tabel 4. Spesifikasi File Nilai

\begin{tabular}{|l|l|l|l|l|l|}
\hline No & Elemen data & Nama field & Type & $\begin{array}{l}\text { Si } \\
\text { ze }\end{array}$ & $\begin{array}{l}\text { Ket- } \\
\text { erangan }\end{array}$ \\
\hline 1 & Id & Id & Int & 10 & Primary key \\
\hline 2 & $\begin{array}{l}\text { Kode_pelajar } \\
\text { an }\end{array}$ & $\begin{array}{l}\text { Kode_pela- } \\
\text { jaran }\end{array}$ & $\begin{array}{l}\text { Var- } \\
\text { char }\end{array}$ & 10 & Foreign key \\
\hline 3 & Kode_guru & Kode_guru & $\begin{array}{l}\text { Var- } \\
\text { char }\end{array}$ & 10 & Foreign key \\
\hline 4 & Kode_siswa & Kode_siswa & $\begin{array}{l}\text { Var- } \\
\text { char }\end{array}$ & 10 & Foreign key \\
\hline 5 & Kelas & Kelas & Int & 1 & \\
\hline 6 & Nilai_tugas1 & $\begin{array}{l}\text { Nilai_tu- } \\
\text { gas1 }\end{array}$ & Int & 3 & \\
\hline 7 & Nilai_tugas2 & $\begin{array}{l}\text { Nilai_tu- } \\
\text { gas2 }\end{array}$ & Int & 3 & \\
\hline 8 & Nilai_uts & Nilai_uts & Int & 3 & \\
\hline 9 & Nilai_uas & Nilai_uas & Int & 3 & \\
\hline 10 & Keterangan & Keterangan & $\begin{array}{l}\text { Var- } \\
\text { char }\end{array}$ & 50 & \\
\hline 11 & $\begin{array}{l}\text { Ta- } \\
\text { hun_ajaran }\end{array}$ & $\begin{array}{l}\text { Tahun_aja- } \\
\text { ran }\end{array}$ & $\begin{array}{l}\text { Var- } \\
\text { char }\end{array}$ & 10 & \\
\hline
\end{tabular}

- $\quad$ Spesifikasi File Pelajaran

Tabel 5. Spesifikasi File Pelajaran

\begin{tabular}{|l|l|l|l|l|l|}
\hline No & Elemen data & Nama field & Type & $\begin{array}{l}\text { Siz } \\
\text { e }\end{array}$ & $\begin{array}{l}\text { Ket- } \\
\text { erangan }\end{array}$ \\
\hline 1 & $\begin{array}{l}\text { Kode_pelajar } \\
\text { an }\end{array}$ & $\begin{array}{l}\text { Kode_pelajar } \\
\text { an }\end{array}$ & Varchar & 10 & $\begin{array}{l}\text { Primary } \\
\text { key }\end{array}$ \\
\hline 2 & $\begin{array}{l}\text { Na- } \\
\text { ma_pelajara } \\
\text { n }\end{array}$ & $\begin{array}{l}\text { Na- } \\
\text { ma_pelajara } \\
\text { n }\end{array}$ & Varchar & 25 & \\
\hline 3 & Kelas & Kelas & Int & 1 & \\
\hline 4 & Keterangan & Keterangan & Varchar & 50 & \\
\hline 5 & Id_admin & Id_admin & Int & 10 & \\
\hline
\end{tabular}

Spesifikasi File Wali_Kelas

Tabel 6. Spesifikasi File Wali Kelas

\begin{tabular}{|l|l|l|l|l|l|}
\hline No & Elemen data & Nama field & Type & Size & Keterangan \\
\hline 1 & Id_wali_kelas & Id_wali_kelas & Int & 10 & Primary key \\
\hline 2 & Kode_guru & Kode_guru & Varchar & 10 & Foreign key \\
\hline 3 & Kelas & Kelas & Int & 1 & \\
\hline 4 & Username & Username & Varchar & 25 & \\
\hline 5 & Password & Password & Varchar & 50 & \\
\hline 6 & Id_admin & Id_admin & Int & 10 & \\
\hline
\end{tabular}

- Spesifikasi File Informasi_Wali_Kelas

Tabel 7. Spesifikasi File Informasi Wali kelas

\begin{tabular}{|l|l|l|l|l|l|}
\hline No & Elemen Data & Nama Field & Type & Size & Keterangan \\
\hline 1 & $\begin{array}{c}\text { Id_informasi } \\
\text { _wali_kelas }\end{array}$ & $\begin{array}{c}\text { Id_informasi } \\
\text { _wali_kelas }\end{array}$ & Int & 10 & Primary Key \\
\hline
\end{tabular}

\begin{tabular}{|l|l|l|l|l|l|}
\hline 2 & $\begin{array}{l}\text { Id_wali_kela } \\
\mathrm{s}\end{array}$ & $\begin{array}{l}\text { Id_wali_kela } \\
\mathrm{s}\end{array}$ & $\begin{array}{l}\text { Var- } \\
\text { char }\end{array}$ & 10 & Foreign key \\
\hline 3 & $\begin{array}{l}\text { Tgl_informas } \\
\mathrm{i}\end{array}$ & $\begin{array}{l}\text { Tgl_informas } \\
\mathrm{i}\end{array}$ & Date & & \\
\hline 4 & Informasi & Informasi & Text & 50 & \\
\hline
\end{tabular}

- $\quad$ Spesifikasi File Informasi

Tabel 8. Spesifikasi File Informasi

\begin{tabular}{|c|l|l|l|l|l|}
\hline No & Elemen data & Nama field & Type & Size & Keterangan \\
\hline 1 & Id_informasi & Id_informasi & Int & 10 & Primary key \\
\hline 2 & Id_admin & Id_admin & Int & 10 & Foreign key \\
\hline 3 & Tgl_informasi & Tgl_informasi & Date & & \\
\hline 4 & Informasi & Informasi & Text & & \\
\hline
\end{tabular}

\subsection{Tahap Implementasi}

- Implementasi Halaman Utama Sistem Informasi Akademik

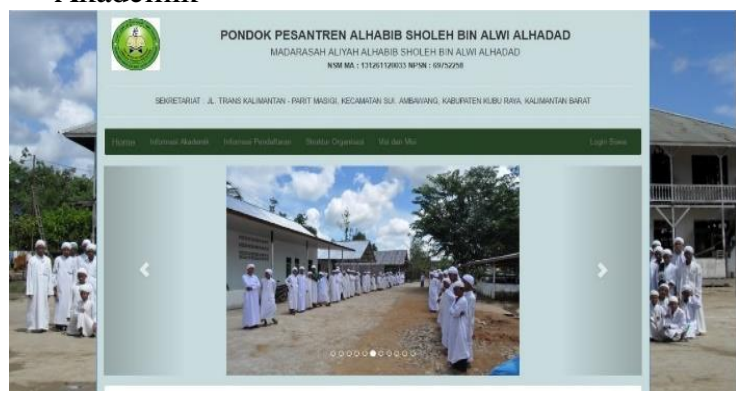

Gambar 9. Implementasi Halaman Utama Sistem Informasi Akademik

Halaman (page) pertama dalam website ini adalah beranda, yang dimana dapat dilihat secara umum. Yang berisikan Sejarah Singkat, Informasi Pendaftaran, Informasi Akademik Dan Visi Misi Pondok Pesantren Alhabib Sholeh Bin Alwi Alhaddad. 
- Implementasi Halaman Ruang Siswa

Halaman ruang siswa ini dapat di akses oleh siswa yang memiliki Username dan passwoed yang telah di peroleh melalui pendaftaran. Agar siswa dapat melihat sistem informasi akademik dan nilai siswa masing-masing.

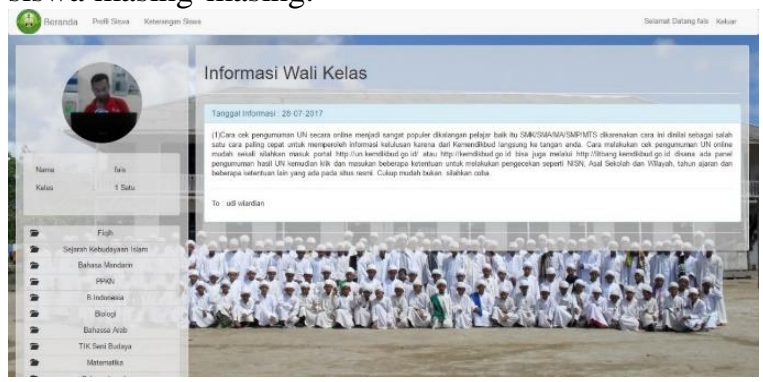

Gambar 10. Implementasi Halaman Ruang Siswa

- Implementasi Halaman Ruang Utama Guru

Halaman guru ini hanya dapat dilakukan oleh guru yang telah terdaftar namanya pada data guru, ketika guru memasukan username dan password dengan benar maka guru dapat masuk kedalam website guru

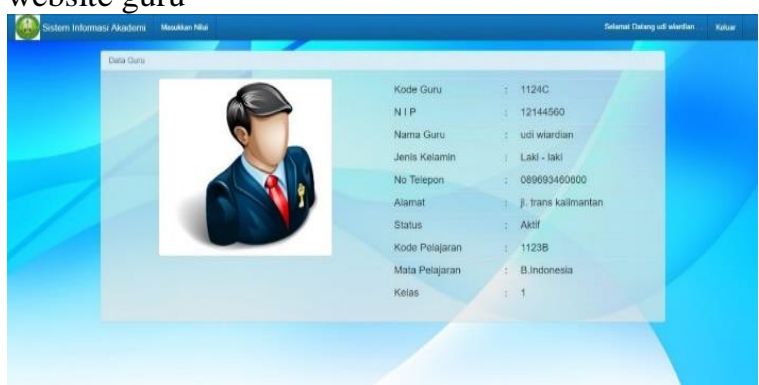

Gambar 11.

Implementasi Halaman Beranda Guru

- Implementasi Halaman Ruang Wali Kelas

Halaman Ruang wali kelas ini hanya dapat dilakukan oleh guru yang telah menjadi wali kelas, untuk login masukan username dan password dengan benar maka guru dapat masuk kedalam website guru.

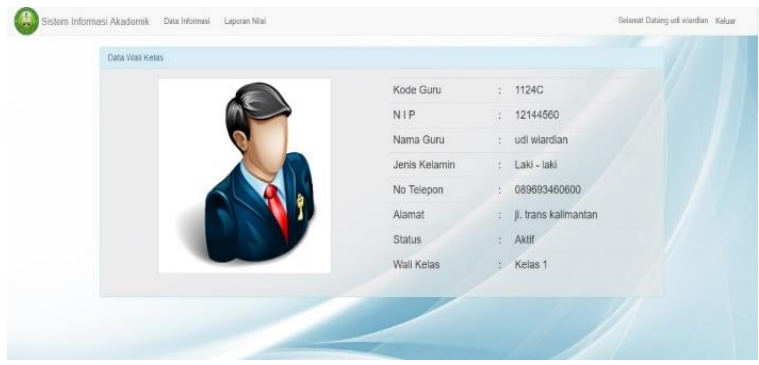

Gambar 12.

Implementasi Halaman Ruang Wali Kelas

- Implementasi Halaman Login Admin

Halaman login admin dapat di akses oleh admin yang bertanggung jawab sepenuhnya atas sistem informasi akademik pondok pesantren melalui username dan password yang telah dimilkinya.

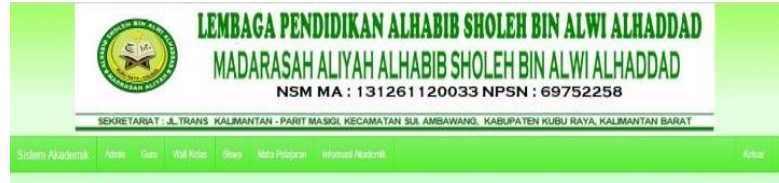

Selamat Datang Administrator Sistem Akademik
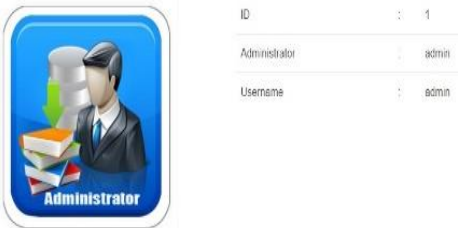

Gambar 13. Implementasi Halaman Ruang

Admin

\subsection{Tahap Pengujian}

a. Halaman Login Admin

Pengujian ini dimaksudkan untuk menguji apakah ketika admin salah memasukkan kode nik dan password bahkan sama sekali tidak diisi dan langsung melakukan proses login, maka sistem akan menampilkan pesan menolak masuk ke sistem. Sehingga tidak sembarang orang bisa masuk ke system, dan setelah diuji dengan berbagai sekenario maka halaman ini berjalan dengan baik

b. Pengujian Fungsional tambah Siswa

Pengujian ini dimaksudkan untuk menguji apakah jika admin mengisi data siswa dan tidak mengisi salah satu data yang tersedia atau tidak mengisi semua data dan langsung melakukan proses, maka sistem akan menampilkan pesan peringatan untuk mengisi data yang masih kosong, sehingga data siswa harus lengkap diisi.

c. Pengujian Fungsional Tambah Informasi

Akademik

Pengujian ini dimaksudkan untuk menguji apakah jika user mengisi data tambah informasi dan tidak mengisi salah satu data yang tersedia atau tidak mengisi semua data dan langsung melakukan proses terbitkan, maka sistem akan menampilkan pesan peringatan untuk mengisi data yang masih kosong, sehingga data tambah informasi harus lengkap diisi.

d. Pengujian Fungsional Login Guru

Pengujian ini dimaksudkan untuk menguji apakah ketika guru salah memasukkan Nip dan tanggal lahir bahkan sama sekali tidak diisi dan langsung melakukan proses login, maka sistem akan menampilkan pesan menolak masuk ke sistem. Sehingga tidak sembarang orang bisa masuk ke sistem e. Pengujian Fungsional Masukan Nilai

Pengujian ini dimaksudkan untuk menguji apakah ketika guru memasukan nilai atau tidak diisi dan melakukan proses simpan, maka sistem akan menampilkan peringatan untuk mengisi data yang masih kosong, sehingga data nilai harus diisi. 
f. Pengujian Fungsional Login Wali Kelas

Pengujian ini dimaksudkan untuk menguji apakah ketika wali kelas salah memasukkan Nis dan tanggal lahir bahkan sama sekali tidak diisi dan langsung melakukan proses login, maka sistem akan menampilkan pesan menolak masuk ke sistem. Sehingga tidak sembarang orang bisa masuk ke sistem

g. Pengujian Fungsional Tambah Informasi Wali

Kelas

Pengujian ini dimaksudkan untuk menguji apakah jika wali kelas mengisi data informasi dan tidak mengisi salah satu data yang tersedia atau tidak mengisi semua data dan langsung melakukan proses simpan, maka sistem akan menampilkan pesan peringatan untuk mengisi data yang masih kosong, sehingga data tambah informasiharus lengkap diisi.

h. Pengujian Fungsional Login Siswa

Pengujian ini dimaksudkan untuk menguji apakah ketika siswa salah memasukkan Nis dan tanggal lahir bahkan sama sekali tidak diisi dan langsung melakukan proses login, maka sistem akan menampilkan pesan menolak masuk ke sistem. Sehingga tidak sembarang orang bisa masuk ke sistem.

i. Pengujian Fungsional Profil Siswa

Pengujian ini dimaksudkan untuk menguji apakah jika admin mengisi data siswa dan tidak mengisi salah satu data yang tersedia atau tidak mengisi semua data dan langsung melakukan proses, maka sistem akan menampilkan pesan peringatan untuk mengisi data yang masih kosong, sehingga data siswa harus lengkap diisi.

\section{KESIMPULAN DAN SARAN}

\subsection{Kesimpulan}

Setelah melakukan analisa di Pondok Pesantren Al-habib Sholeh Bin Alwi Alhaddad penulis memcoba memeberikan solusi sebagai berikut:

- Metodologi SDLC waterfall sangat enak dipahami dan digunakan terutama dalam proses pembuatan system Informasi

- Dengan diterapkannya sistem informasi akademik ini dapat membantu pengolahan data sebelumnya menjadi terkomputerisasi.

- Dengan adanya sistem informasi akademik ini Proses pencarian data guru, data siswa, data nilia dan informasi lebih efektif karna apenyimpanan data sudah dalam bentuk database.

- Dengan adanya sistem informasi akademik ini Pengambilan keputusan penilaian semakin cepat dan mudah karena sistem perhitungan penilaian sudah otomatis dan sudah di sesuaikan dengan keputusan sekolah.

- Dengan adanya sistem infrmasi akademik ini Pihak siswa dan wali siswa dapat mengetahui perkembangan nilai putranya dan informasi pondok pesantren lebih mudah dan cepat dengan mengakses website pondok Pesantren.
Setelah penulis menyusun dan membuat suatu sistem informasi akademik, penulis dapat mengetahui apa yang menjadi kelebihan dan kekurangan dari sistem yang penulis buat. Adapun saran yang dapat penulis sampaikan pada sistem informasi akademik pada Pondok Pesantren Alhabib Sholeh Bin Alwi Alhaddad, adalah sebagai berikut :

- Di harapakan program sistem inforasi akademik yang telah dirancang dapat dikembangkan kembali menjadi lebih sempurna dalam berbagai hal sperti desain dan tampilan program yang dapat diperbaikai menjadi lebih bagus supaya user tidak jenuh dan agar sedikit lebih menarik.

- Diharapkan pihak sekolah dapat mengembangkan sistem informasi akademik yang lebih kompleks seperti Penambahan SMS Getway untuk memberikan informasi seputar kegiatan akademik kepada guru dan atau kepada orang tua siswa,

- Di harapkan pihak sekolah Penambahan Ujian online pada sistem informasi akademik. Layanan ini akan sangat berguna untuk menghemat sumber daya, seperti kertas dan tenaga untuk melaksanan kegiatan ujian serta menilai hasil ujian setiap peserta ujian (siswa).

- Di harapkan pihak pondok pesantren dapat mengembangkan sistem ini dengan menerapakn keseluruh sekolah sperti pada MI, MTs dan seluruh sntri untuk pendataan.

\section{REFERENSI}

Sukamto,dan M. Shalahuddin. 2013. Rekayasa Perangkat Lunak Terstruktur Dan Berorientasi Objek. Bandung: Informatika.

Evi, Holina., Dan Malabay. Analisis Pengembangan Aplikasi Web Untuk Profil Perusahaan, 2009 (Semnas If), (122-127).

Rizky, Soetam. Konsep Dasar Rekayasa Perangkat Lunak. Jakarta: Prestasi Pustaka, 2011.

Simarmata, Janner. 2010. Rekayasa Perangkat Lunak. Yogyakarta: Cv. Andi Offset.

Irawan. 2011. Panduan Berinternet Untuk Orang Awam. Palembang : Maxikom.

Saputra, Agus \& Feni Agustin 2011. Pemograman CSS Untuk Pemula. Mediakompotindo, Jakarta.

Priyadi, Yudi, 2013. Kolaborasi Sql Dan Erd Dalam Implementasi Database, Yogyakarta: Andi Yogyakarta.

Pratama, I Putu Agus Eka. 2014. Sistem Informasi Dan Inplementasi. Bandung: Informaitika Bandung.

5.2. Saran 
Prasojo Diat, Lantip., Dan Riyanto. 2011. Teknologi Informasi Pendidikan. Yogyakarta: Gava Media.

Kadir, Abdul., Dan Triwahyuni Ch, Terra, 2013. Pengantar Teknologi Informasi Edisi Revisi. Yogyakarta: Andi.

Saputra Agus. 2012, Sistem Informasi Nilai

Akademik Untuk Panduan Skripsi. 